OPEN ACCESS

Edited by:

Rosemary M. Caron,

University of New Hampshire, USA

Reviewed by:

Sharon Rodner Sznitman,

University of Haifa, Israel

Joanne C. Enticott,

Monash University, Australia

*Correspondence:

Luis Arturo Valdez,

Health Promotion Sciences, Mel and Enid Zuckerman College of Public Health, The University of Arizona, 1295 North Martin Avenue, Tucson, AZ 85727, USA

jolitrac@email.arizona.edu

Specialty section: This article was submitted to Public Health Education and Promotion, a section of the journal Frontiers in Public Health

Received: 16 February 2015 Accepted: 18 June 2015

Published: 03 July 2015

Citation:

Valdez LA and Langellier BA (2015) Racial/ethnic and socioeconomic disparities in mental health in Arizona. Front. Public Health 3:170 doi: 10.3389/fpubh.2015.00170

\section{Racial/ethnic and socioeconomic disparities in mental health in Arizona}

\author{
Luis Arturo Valdez* and Brent A. Langellier \\ Health Promotion Sciences, Mel and Enid Zuckerman College of Public Health, The University of Arizona, Tucson, AZ, USA
}

Background: Mental health issues are a rapidly increasing problem in the US. Little is known about mental health and healthcare among Arizona's Hispanic population.

Methods: We assess differences in mental health service need, mental health diagnoses, and illicit drug use among 7,578 White and Hispanic participants in the 2010 Arizona Health Survey.

Results: Prevalence of mild, moderate, or severe psychological distress was negatively associated with SES among both Whites and Hispanics. Overall, Hispanics were less likely than Whites to have been diagnosed with a mental health condition; however, diagnosis rates were negatively associated with SES among both populations. Hispanics had considerably lower levels of lifetime illicit drug use than their White counterparts. Illicit drug use increased with SES among Hispanics but decreased with SES among Whites. After adjustment for relevant socio-demographic characteristics, multivariable linear regression suggested that Hispanics have significantly lower Kessler scores than Whites. These differences were largely explained by lower Kessler scores among nonEnglish proficient Hispanics relative to English-speaking populations. Moreover, logistic regression suggests that Hispanics, the foreign born, and the non-English language proficient have lower odds of lifetime illicit drug use than Whites, the US born, and the English-language proficient, respectively.

Conclusion: The unique social and political context in Arizona may have important but understudied effects on the physical and mental health of Hispanics. Our findings suggest mental health disparities between Arizona Whites and Hispanics, which should be addressed via culturally- and linguistically tailored mental health care. More observational and intervention research is necessary to better understand the relationship between race/ethnicity, socioeconomic status, healthcare, and mental health in Arizona.

Keywords: Hispanic, disparities, drug use, mental health, nativity

\section{Introduction}

Mental health issues are a rapidly increasing problem in the US. The US Department of Health and Human Services defines mental health conditions as characterized by persistent, abnormal alterations in thinking, mood, or behavior associated with distress and impaired functioning (1). Over $24 \%$ of the American population lives with a diagnosed mental health condition, and over $45 \%$ will experience at least one diagnosable condition in their lifetime (2). 
Some adults who suffer from mental health conditions meet diagnostic criteria for serious mental illness (SMI). SMI refers to adults who currently or at any time during the past year have a diagnosable mental, behavioral, or emotional disorder that has resulted in functional impairment that limits major life activities. Major depression, bipolar disorder, and schizophrenia are among conditions that typically meet this definition. The annual costs associated with SMI are estimated to be in excess of $\$ 300$ billion as of 2012, excluding the cost attributable to physical health comorbidities (3). The National Survey on Drug Use and Health (NSDUH) found that there were estimated 9.6 million US adults aged 18 or older in the U.S. with a SMI in 2012. American Indian/Alaskan Natives (8.5\%) suffer from the highest prevalence of SMI, followed by Hispanics (4.4\%) Whites (4.2\%), and African Americans (3.4\%) (4).

The prevalence mental health conditions are comparable between Hispanic and Whites; however, $18 \%$ of Whites use mental health services compared to just $7 \%$ of Hispanics (4). Estimates suggest that over 11 million adults aged 18 or older have an unmet need for mental health care (4). Access and use of mental health services is related to household poverty, living in impoverished neighborhoods, and lack of insurance or sufficient money to pay for necessary services (5-9). However, while lack of economic resources are a factor, Ojeda et al. found that service use among Hispanics is also affected by social barriers (e.g., stigma) (10). Furthermore, Hispanics that live in poor neighborhoods have less access to mental health services than their White counterparts $(5,11)$. Nevertheless, even when services are readily available, they often are not culturally or linguistically appropriate (6), and Hispanic patients are less likely to obtain adequate care when compared to their non-Hispanic counterparts (12). This phenomenon has been attributed to unavailability of Spanish language services (13), the lack of interpreters (6), scarcity of culturally competent service providers (6), and perceived discrimination (11). While many studies have found that those who do not speak English have lower probabilities of receiving needed services, an even more dramatic relationship was found between non-English speaking Hispanics and English-only Hispanics (14). Moreover, an even greater gap was found between non-English speaking Hispanic immigrants compared to US-born English-speaking Hispanics (15).

Hispanics make up $16.9 \%$ of the national population and $30.2 \%$ of the population of the state of Arizona (16). Projections suggest that the Hispanic population will double in the next 40 years and that by 2050 one in every three people living in the US will be Hispanic $(16,17)$. The large growth of the Hispanic population, coupled with its disproportionate burden of mental health issues and poor access to mental health services, underscores the need to identify proactive, comprehensive solutions. Thus, it is critical to understand the prevalence of diagnosed and undiagnosed mental health conditions, and access and use of mental health services among Hispanics. Because of the dire effects of mental health conditions, a first step toward developing effective strategies to improve mental health services among Hispanics is to further understand the extent and nature of disparities faced by this population. Moreover, it is imperative that the health of the Hispanic population in the state of Arizona, specifically, is further explored due explicitly to the sociopolitical implications of its proximity to the US-Mexico border, which have been found to have a detrimental impact on mental and physical health outcomes $(18,19)$.

In this study, our objectives are to (1) assess need, access, and utilization of mental health services as well as illicit drug use among Hispanic and White adults in Arizona, (2) assess whether disparities in mental health and illicit drug use are explained by socio-demographic, acculturative, and economic differences between Hispanic and White adults in Arizona.

\section{Conceptual Framework}

We present the conceptual framework that guides our analyses in Figure 1. As per previous studies (4-15) we posit that there is a relationship between race/ethnicity and mental health. Specifically, literature suggests that there are Hispanic-White disparities in need, access, and use of mental health services and substance abuse (4-6, 8-15). Since previous studies have documented a relationship between age, marital status, and behavioral health (1-3), we further posit that a portion of these disparities can be explained by demographic differences between the Hispanic and White populations. Furthermore, the acculturation literature has documented different risk profiles between US-born, more acculturated Hispanics and their foreign-born, less acculturated counterparts (20-25). Therefore, it is also important to understand whether Hispanic-White disparities are explained by nativity and factors related to acculturation (e.g., language use). We further posit that the comparatively lower socioeconomic status of Hispanics places them at increased risk of behavioral health issues relative to Whites. Our final (exploratory) hypothesis is that socioeconomic status may moderate the relationship between race/ethnicity and behavioral health. Specifically, we believe that Hispanics' behavioral health risk will vary based on SES through a number of potential (but unspecified) pathways. For example, low-income Hispanics frequently live in "ethnic enclaves" with high levels of social cohesion and social support, which may act as a buffer against a range of negative physical and mental health

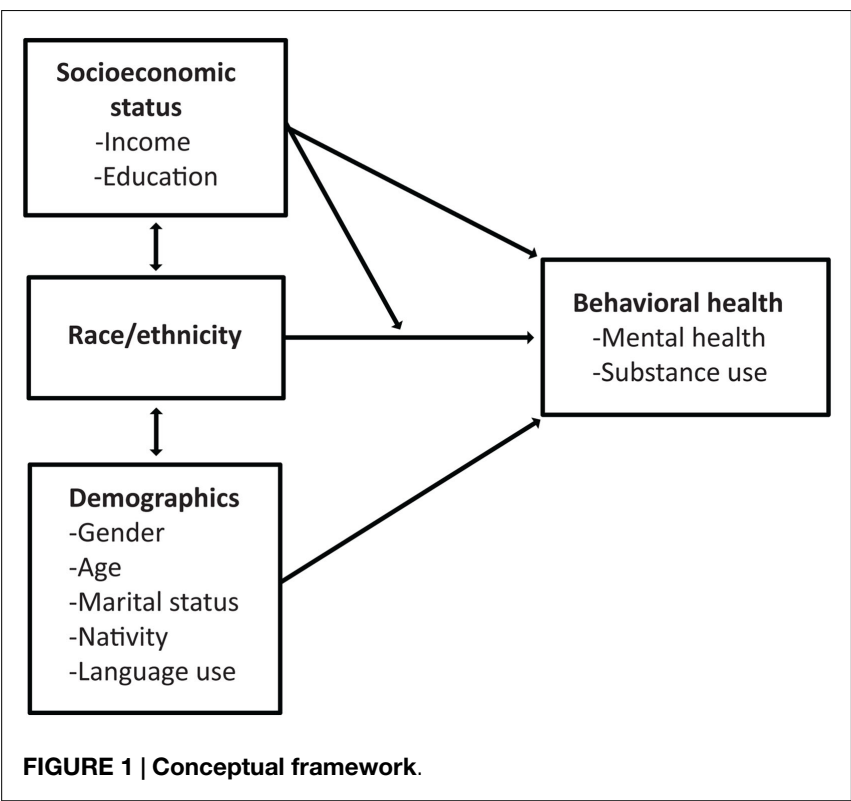


consequences $(26,27)$. Literature also shows differences in the benefits of educational attainment based on race/ethnicity, specifically showing that African Americans and Hispanics may see greater benefits from educational attainment that non-Hispanic Whites $(28,29)$.

\section{Materials and Methods}

\section{Data Source}

Data for this study are from the second wave of the Arizona Health Survey (AHS), conducted from May through August of 2010. The AHS was designed to collect data on a range of indicators, including physical and mental health status, health-related behaviors, insurance coverage, and access to services. In brief the AHS was a population-based, list-assisted random-digit-dial telephone survey representative of the Arizona population living in households (30). Researchers selected residential telephone numbers from six geographic strata defined by counties or groups of counties. One adult respondent (age 18 and over) was selected from each household (30). In households with children (age 6 and under), one child was randomly selected and the adult most knowledgeable about the child's health completed a child interview (30). Samples were selected to obtain at least 8,100 (although 8,215 were collected) adult interviews and 2,000 child interviews (30). AHS data are de-identified and publicly available. Secondary analysis of these data therefore does not constitute human subjects research as defined by federal regulations and does not require IRB review. Further details regarding the AHS study design and data collection are available elsewhere (30).

\section{Sample}

The 2010 AHS included 8,215 adult respondents (30). For this study, we restricted our analyses to 7,578 White $(n=6,022)$ and Hispanic $(n=1,556)$ participants. Black or African American $(n=216)$, Asian/Pacific Islander $(n=99)$, Native American/American Indian $(n=243)$, and a small fraction $(n=79)$ of participants who refused to divulge race/ethnicity information were not included because our primary aim was to assess Hispanic-White disparities in mental health and drug use. Additionally, we further restricted our multivariable analyses to the subsample of participants with complete information about age, marital status, income, education, illicit drug use, mental health diagnosis, nativity, and English-language proficiency resulting in a multivariable analytic sample of $n=6,503$.

\section{Measures}

We assessed mental health service need using the Kessler K6 measure of psychological distress. The K6 has been validated for identification of current mental health problems and need for treatment $(31,32)$. The K6 consists of six questions about anxiety and depressive symptoms that a person has experienced in the most recent 30 -day period $(31,32)$. For example, "During the past 30 days, about how often did you feel hopeless?" Each question is assessed on the following scale: $0=$ none of the time, $1=\mathrm{a}$ little of the time, $2=$ some of the time, $3=$ most of the time, $4=$ all of the time. All six questions are mandatory and total response scores can range from 0 (indicating no distress) through
24 (indicating severe distress) $(31,32)$. According to K6 diagnostic criteria, participants scoring from 0-6 (low range) are likely to be healthy but may benefit from early education-based prevention in order to prevent future mental health issues $(31,32)$. Participants that score 7-14 (mid range) are likely to have mild to moderate mental health disorders and are encouraged to access information and self-help treatment programs $(31,32)$. Participants that score between 15 and 24 (high range) are likely to have a severe mental health disorder and are encouraged to seek immediate help from a mental health professional $(31,32)$. We assessed mental health diagnoses based on participant self-report of diagnosis of bipolar or manic-depressive disorder, anxiety disorder, and clinical depression rates. Illicit drug use was assessed through selfreported lifetime illicit drug use, illicit drug use in the previous 12 months, and in the last 30 days. However, 12-month and 30-day drug use data yield insufficient power to examine between-group disparities, because if participants reported to never have used drugs, omitted questions about more recent drug created a skip pattern that resulted in a small prevalence of self-reported recent drug use. As a result, we elected to use lifetime drug use data. Marijuana, cocaine, crack cocaine, heroin, and methamphetamines were considered illicit drugs for this analysis. We categorized participants' race/ethnicity as Hispanic or White. Federal Poverty Limit (FPL) is a combined measure of household income and family/household size (30). Federal poverty guidelines stipulate that a family of four living on a household income under $\$ 24,250$ lives in a state of poverty (33). FPL was defined based on the following categories present in the AHS data file: $<100 \%$ FPL, 100-199\% FPL, 200-299\% FPL, and $\geq 300 \%$ FPL. We categorized marital status as married, single, and widowed/separated/divorced. We separated educational attainment into less than high school, high school/equivalent, and more than high school. We also categorized English language proficiency as (1) native speaker or speaks very well, (2) speaks well, (3) not well, and (4) not at all. Lastly, nativity was categorized into US born and foreign born.

\section{Statistical Analyses}

We present means and 95\% confidence intervals of all continuous variables and the percentage distribution of all categorical variables. We use conditional means and cross-tabulation to assess whether mental health outcomes and illicit drug use vary by race/ethnicity (i.e., Hispanic vs. White). We use t-tests to assess the statistical significance of variation across groups. We use multivariable regression models to examine the relationship between race/ethnicity and behavioral health outcomes. For each outcome (i.e., Kessler K6 scores and self-reported lifetime drug use), we present a series of four regression models. Consistent with our conceptual framework, we conduct "stepwise" analyses whereby additional sets of explanatory variables are added to each subsequent model. In the first model for each outcome, we adjust for race/ethnicity and demographic factors that vary between Hispanics and Whites (i.e., gender, age, and marital status). In the second model, we further adjust for socioeconomic characteristics (i.e., household income, measured as a percentage of FPL, and educational attainment). In the third model, we further adjust for English language proficiency and nativity to understand the extent to which Hispanic-White disparities that remain after adjustment 
for other factors may be attributable to nativity and acculturation. In the fourth model, we include an interaction between race/ethnicity and household income to assess whether Hispanics' level of behavioral health risk varies across income strata. In the final model, we include an interaction between race/ethnicity and educational attainment to assess whether Hispanic's level of behavioral health risk varies by educational attainment level.

The outcome in the multivariable linear regression models is the square root of the Kessler K6 score. We use the square root because the K6 is right tailed and violates the normality assumption of linear regression; using the square root transformation results in a more normally distributed outcome. We elected not to use the 12-month and 30-day drug use data because the number of self-reported drug use in the last 12 months and 30 days, respectively, yields insufficient power to examine between-group disparities. To account for non-response, probability of selection, and the complex survey design, we used weights present in the AHS data file. All data analyses were conducted using STATA 13 (34).

\section{Results}

Table 1 contains demographic characteristics for the 1,480 Hispanic and 4,590 White participants in the sample. Hispanic respondents were significantly $(p<0.001)$ younger than White respondents. Over $75 \%$ of Hispanic respondents were under the age of 50 compared to $51 \%$ of Whites. Nearly $25 \%$ of Hispanic respondents were single compared to $15 \%$ of Whites $(p=0.002)$. Only $10 \%$ of Whites lived below the $100 \%$ FPL compared to $33 \%$ of Hispanics $(p<0.001)$. Over $55 \%$ of Whites lived above the $300 \%$ FPL while only $21 \%$ of Hispanics fell into the same category $(p<0.001)$. Approximately $95 \%$ of Whites were born in the US compared to $44 \%$ of Hispanics $(p<0.001)$. Nearly all Whites considered English to be their primary language compared to only $36 \%$ of Hispanics $(p<0.001)$. Finally while nearly all Whites were native speakers or speak English very well, only $49 \%$ of Hispanic respondents reported that they speak English very well $(p<0.001)$. No significant differences were found in the gender distribution of the two populations.

Table 1 also includes measures of psychological distress, mental health diagnosis, and self-reported lifetime use of illegal substances. There were differences in calculated K6 scores, diagnosis rates, and illicit drug use between Hispanics and Whites $(p=0.022)$. Nearly $76 \%$ of Whites reported a low K6 score compared to $69 \%$ of Hispanics. The mild/moderate/severe K6 score was also higher for Hispanics at 26\% compared to 20\% for Whites. Severe K6 score was similar for both populations. Hispanics had significantly lower rates of mental health diagnosis at $13 \%$ compared to Whites at nearly $18 \%(p=0.014)$. Hispanics had lower rates of lifetime illicit drug use than Whites $(p<0.001)$. Hispanics also had lower rates of illicit drug use in the last year at $15 \%$ compared to nearly $30 \%$. However, Hispanics had slightly higher use within the last month compared to Whites $(p<0.001)$.

Table 2 shows measures for psychological distress, mental health diagnosis and self-reported lifetime use of illegal substances stratified by FPL. When stratified by FPL, prevalence of K6 scores indicating mild/moderate/severe psychological distress decreased along with increased FPL for both populations.
Hispanics improved from $38.74 \%$ when under the $100 \%$ FPL to $19.87 \%$ at or above $300 \%$ FPL $(p=0.003)$. Whites improved from $42.64 \%$ at under the $100 \%$ FPL to $16.89 \%$ when living at or above $300 \%$ FPL $(p<0.001)$. While Hispanics had lower rates of mental health diagnosis across all FPL levels when compared to Whites, diagnosis decreased along with increased FPL for both populations. Diagnosis rates for Hispanics decreased by nearly half, rising from $15 \%$ when living below the $100 \%$ FPL to $8 \%$ when living at or above the $300 \%$ FPL $(p=0.103)$. Similar trends are seen for Whites that went from nearly $29 \%$ while under $100 \%$ FPL to $14 \%$ at or above $300 \%$ FPL $(p<0.001)$. When living under the $100 \%$ FPL Hispanics have considerably lower levels of lifetime illicit drug use than their White counterparts at $8 \%$ compared to nearly $42 \%$. However, illicit drug use levels change along with FPL. Hispanics show an increase from $8 \%$ at $<100 \%$ FPL to $36 \%$ $(p<0.001)$ when living at or above the $300 \%$ FPL, while Whites decreased from nearly $42 \%$ at $<100 \%$ FPL to $35 \%(p=0.205)$ at $300 \%+$.

Table 3 includes the results of five multivariable linear regression models that assess the relationship between race/ethnicity and the square root of the Kessler score after adjustment for gender, age, and marital status (Model 1), adjustment for family income and educational attainment (Model 2), further adjustment for nativity and English language proficiency (Model 3). The fourth model includes interaction terms between race/ethnicity and household income. The final model includes interaction terms between race/ethnicity and educational attainment. Model 1 suggests that after adjustment for gender, age, and marital status, there is no significant relationship between race/ethnicity and Kessler score. After further adjustment for their comparatively lower levels of income and education, however, Model 2 indicates that Hispanics have significantly lower Kessler scores than Whites $(p<0.01)$. Model 3 suggests that lower Kessler scores among Hispanics could be explained by differences in English language proficiency between Hispanics and Whites. The fourth model reveals that Kessler score decreases with age $(p<0.001)$, is greater among the widowed/divorced/separated than among the married $(p<0.001)$, and decreases with household income $(p<0.001)$ and participants' educational attainment $(p<0.01)$. However the fourth model does not reveal a significant effect of the interaction between race/ethnicity and family income. Moreover, the final model does not reveal a significant effect of the interaction between race/ethnicity and educational attainment. Finally, we assessed the variance inflation factor to test for variables that may introduce multicollinearity (i.e., English language proficiency, nativity) and found that all variance inflation factors were below 2.30 and were not a cause for concern.

Table 4 includes the results of five multivariable logistic regression models that assess the relationship between race/ethnicity and lifetime illicit drug use. The first three models include the same sets of covariates as presented in the previous table. The fourth model adjusts for all covariates, but also includes interaction terms to assess whether the relationship between household income and illicit drug use varies between Hispanics and Whites. The fifth model also adjusts for all covariates, and includes interaction terms to assess whether the relationship between educational attainment and illicit drug use varies between Hispanics and 
TABLE 1 | Demographic characteristics, mental health indicators, diagnosis rates, and illicit drug use of White and Hispanic respondents of the 2010 Arizona health survey $(n=6,070)$.

\begin{tabular}{|c|c|c|c|c|c|}
\hline & \multicolumn{2}{|c|}{ White } & \multicolumn{2}{|c|}{ Hispanic } & \multirow[t]{2}{*}{$p$} \\
\hline & $\%$ & $95 \% \mathrm{Cl}$ & $\%$ & $95 \% \mathrm{Cl}$ & \\
\hline Gender & & & & & 0.782 \\
\hline Female & 48.93 & {$[46.52,51.34]$} & 49.68 & {$[44.95,54.42]$} & \\
\hline Male & 51.07 & {$[48.66,53.48]$} & 50.32 & {$[45.58,55.05]$} & \\
\hline Age & & & & & $<0.001$ \\
\hline$<39$ & 33.77 & {$[31.07,36.58]$} & 52.62 & {$[47.95,57.24]$} & \\
\hline $40-49$ & 17.43 & {$[15.73,19.26]$} & 22.48 & {$[19.11,26.20]$} & \\
\hline $50-59$ & 18.48 & {$[16.97,20.09]$} & 14.52 & {$[11.98,17.50]$} & \\
\hline 60-69 & 15.13 & {$[13.96,16.38]$} & 6.10 & {$[4.73,7.85]$} & \\
\hline $70-79$ & 9.10 & {$[8.34,9.93]$} & 3.38 & {$[2.60,4.39]$} & \\
\hline $80+$ & 6.09 & {$[5.44,6.81]$} & 0.89 & {$[0.50,1.43]$} & \\
\hline Marital & & & & & 0.002 \\
\hline Single & 15.40 & {$[13.18,17.91]$} & 19.96 & {$[15.99,24.63]$} & \\
\hline Married & 67.38 & {$[64.92,69.74]$} & 69.29 & {$[64.60,73.62]$} & \\
\hline Wid/div/sep & 17.23 & {$[15.81,18.74]$} & 10.74 & {$[8.61,13.33]$} & \\
\hline Living in poverty & & & & & $<0.001$ \\
\hline Below 100\% FPL & 10.58 & {$[8.90,12.53]$} & 33.47 & {$[29.16,38.07]$} & \\
\hline 100-200\% FPL & 16.70 & {$[14.99,18.57]$} & 28.74 & {$[24.47,33.41]$} & \\
\hline 200-300\% FPL & 16.89 & {$[15.20,18.73]$} & 15.90 & {$[12.53,19.97]$} & \\
\hline More than $300 \%$ & 55.82 & {$[53.38,58.24]$} & 21.90 & {$[18.56,25.65]$} & \\
\hline US-born & 94.58 & {$[93.27,95.65]$} & 44.24 & {$[39.70,48.88]$} & $<0.001$ \\
\hline Primary language & & & & & $<0.001$ \\
\hline English & 96.93 & {$[95.83,97.75]$} & 36.31 & {$[32.08,40.75]$} & \\
\hline Spanish & 1.02 & {$[0.64,1.62]$} & 63.15 & {$[58.69,67.41]$} & \\
\hline English language prof. & & & & & $<0.001$ \\
\hline Native/very well & 98.53 & {$[97.62,99.10]$} & 49.54 & {$[44.81,54.27]$} & \\
\hline Well & 0.46 & {$[0.24,0.85]$} & 14.12 & {$[11.15,17.73]$} & \\
\hline Not well & 0.68 & {$[0.28,1.61]$} & 24.45 & {$[20.36,29.05]$} & \\
\hline Not at all & 0.34 & {$[0.14,0.78]$} & 11.89 & {$[8.81,15.87]$} & \\
\hline Kessler K6 & & & & & 0.022 \\
\hline Low & 75.68 & {$[73.47,77.76]$} & 69.73 & {$[65.15,73.94]$} & \\
\hline Mild/moderate & 20.83 & {$[18.84,22.97]$} & 26.46 & {$[22.35,31.02]$} & \\
\hline Severe & 3.49 & {$[2.76,4.41]$} & 3.81 & {$[2.74,5.28]$} & \\
\hline Diagnosed mental health condition & & & & & 0.014 \\
\hline Diagnosed & 17.97 & {$[16.24,19.84]$} & 13.28 & {$[10.56,16.58]$} & \\
\hline Last illicit drug use & & & & & $<0.001$ \\
\hline Never & 64.97 & {$[62.52,67.34]$} & 80.10 & {$[76.33,83.40]$} & \\
\hline >12 Months & 29.31 & {$[27.07,31.65]$} & 15.59 & {$[12.78,18.88]$} & \\
\hline Within last year & 3.02 & {$[2.17,4.20]$} & 1.39 & {$[0.74,2.58]$} & \\
\hline Within last 30 days & 2.70 & {$[1.92,3.79]$} & 2.92 & {$[1.52,5.56]$} & \\
\hline Sample size & 6,022 & & 1,556 & & \\
\hline
\end{tabular}

TABLE 2 | Kessler score, mental health diagnosis, and illicit drug use by race/ethnicity and federal poverty limit (FPL) of White and Hispanic respondents of the 2010 Arizona health survey $(n=6,070)$.

\begin{tabular}{|c|c|c|c|c|c|c|c|c|c|c|}
\hline \multirow[t]{2}{*}{ Hispanic/White } & \multirow[t]{2}{*}{ FPL } & \multicolumn{2}{|c|}{$\begin{array}{l}\text { Kessler K6 score } \\
\mathrm{mild} / \mathrm{mod} / \mathrm{severe}\end{array}$} & \multirow[t]{2}{*}{$p$} & \multicolumn{2}{|c|}{$\begin{array}{l}\text { Diagnosed with any } \\
\text { behavioral health condition }\end{array}$} & \multirow[t]{2}{*}{$p$} & \multicolumn{2}{|c|}{$\begin{array}{l}\text { Ever use Illicit } \\
\text { drugs }\end{array}$} & \multirow[t]{2}{*}{$\boldsymbol{P}$} \\
\hline & & $\%$ & {$[95 \% \mathrm{Cl}]$} & & $\%$ & $95 \% \mathrm{Cl}$ & & $\%$ & $95 \% \mathrm{Cl}$ & \\
\hline \multirow[t]{4}{*}{ Hispanic } & $<100 \%$ & 38.74 & {$[31.16,46.91]$} & Ref. & 15.49 & {$[10.64,22.02]$} & Ref. & 8.45 & {$[5.57,12.60]$} & Ref. \\
\hline & $100-199 \%$ & 29.92 & {$[22.16,39.03]$} & 0.143 & 11.93 & {$[7.82,17.79]$} & 0.351 & 15.92 & {$[10.87,22.74]$} & 0.025 \\
\hline & $200-299 \%$ & 27.41 & {$[17.95,39.47]$} & 0.144 & 18.44 & {$[11.28,28.68]$} & 0.568 & 28.63 & {$[18.87,40.89]$} & $<0.001$ \\
\hline & $300 \%+$ & 19.87 & {$[12.88,29.36]$} & 0.003 & 7.99 & {$[3.80,16.01]$} & 0.103 & 36.26 & {$[28.07,45.33]$} & $<0.001$ \\
\hline \multirow[t]{4}{*}{ White } & $<100 \%$ & 42.64 & {$[33.92,51.84]$} & Ref. & 28.98 & {$[22.33,36.67]$} & Ref. & 41.94 & {$[32.80,51.68]$} & Ref. \\
\hline & $100-199 \%$ & 34.79 & {$[29.28,40.75]$} & 0.148 & 20.59 & {$[16.69,25.13]$} & 0.041 & 30.50 & {$[25.27,36.29]$} & 0.038 \\
\hline & 200-299\% & 27.09 & {$[22.25,32.55]$} & 0.003 & 21.42 & {$[17.12,26.44]$} & 0.076 & 34.33 & {$[28.72,40.41]$} & 0.178 \\
\hline & $300 \%$ & 16.89 & {$[14.63,19.41]$} & $<0.001$ & 14.06 & {$[11.94,16.48]$} & $<0.001$ & 35.60 & {$[32.63,38.69]$} & 0.205 \\
\hline
\end{tabular}


TABLE 3 | Linear regression models predicting the square root of the Kessler K6 score of Hispanic and White adults in the 2010 AHS ( $n=6,070)$

\begin{tabular}{|c|c|c|c|c|c|}
\hline & $\begin{array}{c}(1) \\
\text { b }[95 \% \mathrm{Cl}]\end{array}$ & $\begin{array}{c}(2) \\
\text { b }[95 \% \mathrm{Cl}]\end{array}$ & $\begin{array}{c}(3) \\
\text { b }[95 \% \mathrm{Cl}]\end{array}$ & $\begin{array}{c}(4) \\
\text { b }[95 \% \mathrm{Cl}]\end{array}$ & $\begin{array}{c}(5) \\
\text { b }[95 \% \mathrm{Cl}]\end{array}$ \\
\hline \multicolumn{6}{|l|}{ Race/ethnicity } \\
\hline White & Ref. & Ref. & Ref. & Ref. & Ref. \\
\hline Hispanic & $\begin{array}{c}0.0205 \\
{[-0.0681,0.109]}\end{array}$ & $\begin{array}{c}-0.128^{\star \star} \\
{[-0.229,-0.0263]}\end{array}$ & $\begin{array}{c}-0.0357 \\
{[-0.142,0.070]}\end{array}$ & $\begin{array}{c}0.049 \\
{[-0.194,0.293]}\end{array}$ & $\begin{array}{c}-0.186 \\
{[-0.419,0.048]}\end{array}$ \\
\hline Female & $\begin{array}{c}0.0636 \\
{[-0.004,0.131]}\end{array}$ & $\begin{array}{c}0.057 \\
{[-0.009,0.124]}\end{array}$ & $\begin{array}{c}0.0579 \\
{[-0.008,0.123]}\end{array}$ & $\begin{array}{c}0.057 \\
{[-0.008,0.122]}\end{array}$ & $\begin{array}{c}0.063 \\
{[-0.003,0.127]}\end{array}$ \\
\hline Age (y) & $\begin{array}{c}-0.0094^{\star \star \star} \\
{[-0.0112,-0.0073]}\end{array}$ & $\begin{array}{c}-0.00887^{\star \star \star} \\
{[-0.0109,-0.0067]}\end{array}$ & $\begin{array}{c}-0.0087^{\star \star \star} \\
{[-0.011,-0.0066]}\end{array}$ & $\begin{array}{c}-0.009^{\star \star \star} \\
{[-0.011,-0.007]}\end{array}$ & $\begin{array}{c}-0.009^{\star \star \star} \\
{[-0.011,-0.006]}\end{array}$ \\
\hline Married & Ref. & Ref. & Ref. & Ref. & Ref. \\
\hline Single & $\begin{array}{c}0.0083 \\
{[-0.104,0.121]}\end{array}$ & $\begin{array}{c}-0.0213 \\
{[-0.136,0.094]}\end{array}$ & $\begin{array}{c}-0.0401 \\
{[-0.153,0.073]}\end{array}$ & $\begin{array}{c}-0.038 \\
{[-0.15,0.073]}\end{array}$ & $\begin{array}{c}-0.044 \\
{[-0.156,0.068]}\end{array}$ \\
\hline Wid/div/sep & $\begin{array}{c}0.310^{\star \star \star} \\
{[0.214,0.406]}\end{array}$ & $\begin{array}{c}0.228^{\star \star \star} \\
{[0.132,0.322]}\end{array}$ & $\begin{array}{c}0.205^{\star \star \star} \\
{[0.109,0.299]}\end{array}$ & $\begin{array}{c}0.204^{\star \star \star} \\
{[0.109,0.299]}\end{array}$ & $\begin{array}{c}0.201^{\star \star \star} \\
{[0.107,0.295]}\end{array}$ \\
\hline \multicolumn{6}{|c|}{ Household income (\% FPL) } \\
\hline$\leq 100 \%$ & & Ref. & Ref. & Ref. & Ref. \\
\hline $101-200 \%$ & & $\begin{array}{c}-0.0927 \\
{[-0.233,-0.048]}\end{array}$ & $\begin{array}{c}-0.116 \\
{[-0.255,-0.023]}\end{array}$ & $\begin{array}{c}-0.075 \\
{[-0.261,0.11]}\end{array}$ & $\begin{array}{c}-0.108 \\
{[-0.245,-0.290]}\end{array}$ \\
\hline 201-300\% & & $\begin{array}{c}-0.113 \\
{[-0.272,-0.045]}\end{array}$ & $\begin{array}{c}-0.159^{*} \\
{[-0.317,-0.016]}\end{array}$ & $\begin{array}{c}-0.115 \\
{[-0.308,-0.078]}\end{array}$ & $\begin{array}{c}-0.156^{\star} \\
{[-0.310,-0.002]}\end{array}$ \\
\hline$>300 \%$ & & $\begin{array}{c}-0.318^{\star \star \star} \\
{[-0.457,-0.179]}\end{array}$ & $\begin{array}{c}-0.361^{\star \star \star} \\
{[-0.501,-0.221]}\end{array}$ & $\begin{array}{c}-0.322^{\star \star \star} \\
{[-0.494,-0.15]}\end{array}$ & $\begin{array}{c}-0.353^{\star \star \star} \\
{[-0.49,-0.215]}\end{array}$ \\
\hline \multicolumn{6}{|l|}{ Education } \\
\hline$<$ High school & & Ref. & Ref. & Ref. & Ref. \\
\hline High school & & $\begin{array}{c}-0.0872 \\
{[-0.235,0.0602]}\end{array}$ & $\begin{array}{c}-0.164^{\star} \\
{[-0.310,0.018]}\end{array}$ & $\begin{array}{c}-0.166^{\star} \\
{[-0.311,-0.021]}\end{array}$ & $\begin{array}{c}-0.276^{\star *} \\
{[-0.481,0.015]}\end{array}$ \\
\hline >High school & & $\begin{array}{c}-0.158^{\star} \\
{[-0.302,-0.0134]}\end{array}$ & $\begin{array}{c}-0.236^{\star \star} \\
{[-0.381,-0.091]}\end{array}$ & $\begin{array}{c}-0.239^{\star \star \star} \\
{[-0.383,-0.094]}\end{array}$ & $\begin{array}{c}-0.313^{\star \star} \\
{[-0.500,-0.118]}\end{array}$ \\
\hline Foreign born & & & $\begin{array}{c}-0.091 \\
{[-0.229,-0.046]}\end{array}$ & $\begin{array}{c}-0.091 \\
{[-0.218,0.183]}\end{array}$ & $\begin{array}{c}-0.09 \\
{[-0.227,0.071]}\end{array}$ \\
\hline \multicolumn{6}{|l|}{ English language } \\
\hline Native/very well & & & Ref. & Ref. & Ref. \\
\hline well & & & $\begin{array}{c}-0.01 \\
{[-0.215,-0.195]}\end{array}$ & $\begin{array}{c}-0.025 \\
{[-0.133,0.183]}\end{array}$ & $\begin{array}{c}-0.019 \\
{[-0.227,0.188]}\end{array}$ \\
\hline Not well & & & $\begin{array}{c}-0.14 \\
{[-0.364,0.083]}\end{array}$ & $\begin{array}{c}-0.163 \\
{[-0.389,0.064]}\end{array}$ & $\begin{array}{c}-0.122 \\
{[-0.342,0.098]}\end{array}$ \\
\hline Not at all & & & $\begin{array}{c}-0.39^{* \star} \\
{[-0.655,-0.126]}\end{array}$ & $\begin{array}{c}-0.418^{\star \star} \\
{[-0.686,-0.149]}\end{array}$ & $\begin{array}{c}-0.342^{\star \star} \\
{[-0.613,-0.071]}\end{array}$ \\
\hline \multicolumn{6}{|l|}{ Interaction terms } \\
\hline Hispanic* 101-200\% & & & & $\begin{array}{c}-0.088 \\
{[-0.356,0.180]}\end{array}$ & \\
\hline Hispanic* 201-300\% & & & & $\begin{array}{c}-0.115 \\
{[-0.426,0.194]}\end{array}$ & \\
\hline Hispanic ${ }^{\star}>300 \%$ & & & & $\begin{array}{c}-0.107 \\
{[-0.382,0.167]}\end{array}$ & \\
\hline Hispanic* high school & & & & & $\begin{array}{c}0.258 \\
{[-0.015,0.531]}\end{array}$ \\
\hline Hispanic* >high school & & & & & $\begin{array}{c}0.132 \\
{[-0.127,0.392]}\end{array}$ \\
\hline Constant & $\begin{array}{c}2.43^{\star \star \star} \\
{[2.286,2.583]}\end{array}$ & $\begin{array}{c}2.77^{\star \star \star} \\
{[2.55,2.99]}\end{array}$ & $\begin{array}{c}2.877^{\star \star \star} \\
{[2.667,3.089]}\end{array}$ & $\begin{array}{c}2.848^{\star \star \star} \\
{[2.602,3.09]}\end{array}$ & $\begin{array}{c}2.94^{\star \star \star} \\
{[2.696,3.196]}\end{array}$ \\
\hline
\end{tabular}

95\% confidence intervals in brackets. ${ }^{*} p<0.05 ;{ }^{* *} p<0.01 ;{ }^{* * *} p<0.001$

Whites. The results presented in Model 1 suggest that, after adjustment for gender, age, and marital status, Hispanics are much less likely than Whites to have used illicit substances in their lifetimes. This relationship endures after further adjustment for income and educational attainment (Model 2), but is attenuated after further adjustment for nativity and English language proficiency (Model 3). However, adjustment in model 3 suggests that Hispanics $(p<0.05)$ the foreign-born, $(p<0.001)$, and the non-English proficient $(p<0.001)$ have lower odds of illicit drug use when compared to Whites, the US-born, and the English language proficient, respectively. Interestingly, the household income odds ratios in Model 4 suggest that there is no significant relationship between household income and illicit drug use among Whites; however, the interaction terms suggest that illicit drug use increases with 
TABLE 4 | Logistic regression models predicting lifetime illicit drug use among Hispanic and White adults in the 2010 AHS.

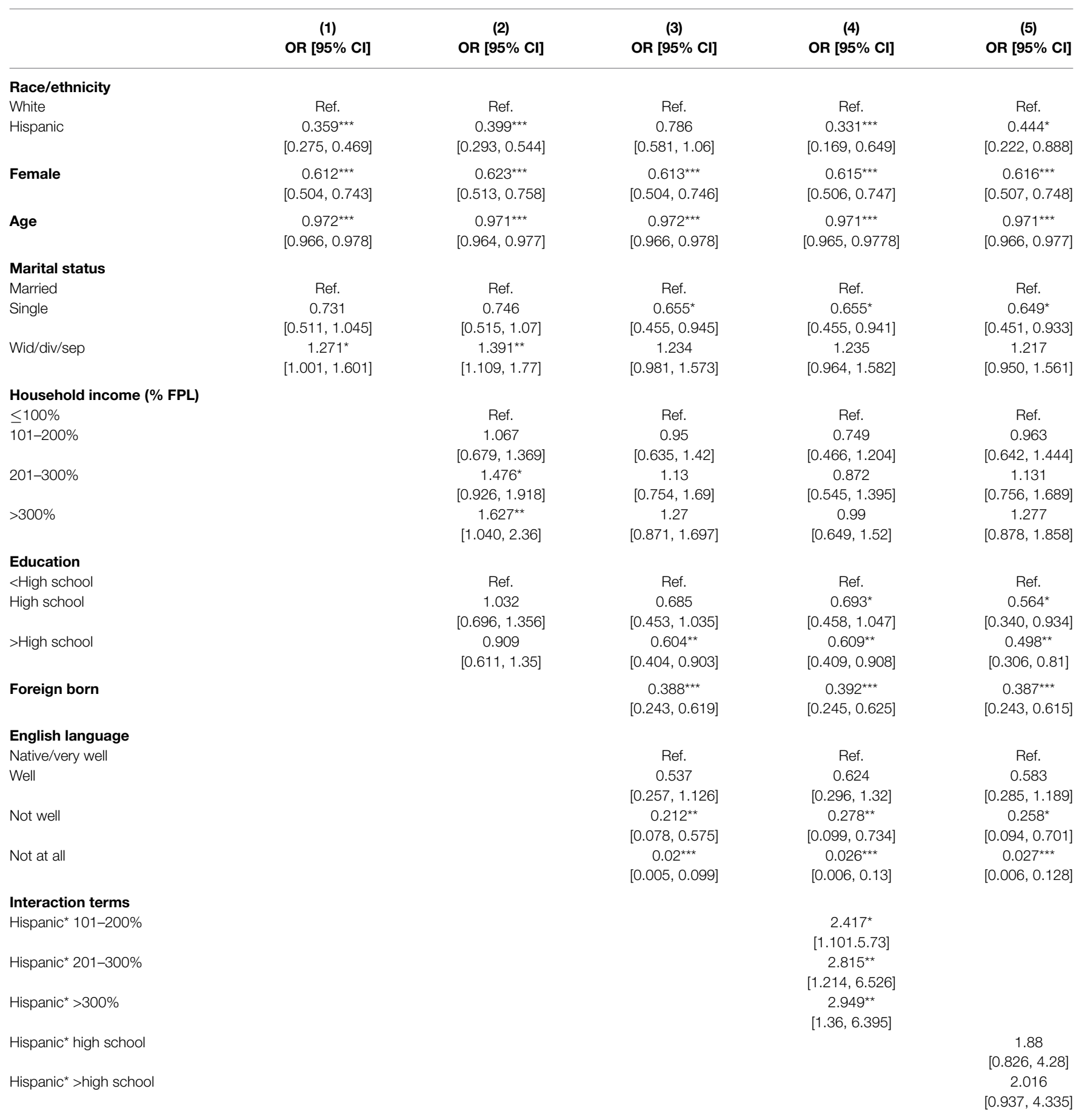

95\% confidence intervals in brackets. ${ }^{*} p<0.05 ;{ }^{* *} p<0.01 ;{ }^{* * *} p<0.001$.

household income among Hispanics. For example, Hispanics with annual household income $>300 \%$ FPL have nearly three times the odds of having ever used illicit substances relative to those with income $\leq 100 \%$ FPL $(p<0.001)$. The final model does not uncover a significant effect of the interaction between race/ethnicity and educational attainment. Finally, we also assessed the variance inflation factor to test for variables that may introduce multicollinearity (i.e., English language proficiency, nativity) and found that all variance inflation factors were below 2.31 and were not a cause for concern.

\section{Discussion}

We found that although mental health diagnosis rates for Hispanics were lower, more Hispanics reported a higher K6 score than their White counterparts, which may indicate a disproportionate 
and unmet need for mental healthcare services. Our findings are consistent with the literature showing that Hispanics face an unmet need for mental healthcare services that is more than double that of their White counterparts $(6,8,9)$. Moreover, high psychological distress that does not manifest itself into proportionately high diagnosis rates can also mean that there is an underutilization of services by Hispanic respondents. This is also consistent with research showing that, even when services are readily accessible, Hispanics have lower mental health service utilization rates than Whites $(6,10,13)$.

Among both Hispanics and Whites, K6 scores were negatively associated with household income. Our findings suggest that low psychological distress and good mental health may be positively associated with increases in socioeconomic position, which is consistent with findings in the available literature $(6,7)$. Moreover, research has also shown that foreign-born Hispanics are at significantly lower risk for psychiatric morbidity than US-born Whites (24), which is also consistent with our findings showing better K6 scores for foreign-born Hispanics than US-born Hispanics and US-Born Whites. Furthermore, research also suggests that acculturation among Hispanics is associated with an increase in the prevalence of psychiatric disorders and illicit drug use (20, 24). Although the mechanism through which acculturation affects mental health is understudied, researchers have posited that Hispanic culture may be protective and exposure to and adoption of some elements of U.S. culture may have detrimental effects on psychiatric morbidity (25).

Hispanic participants in our study reported lower rates of lifetime and current use of illicit substances than their White counterparts. This is consistent with the research showing that the prevalence of illicit drug use is lower among US Hispanics than Whites (35-37). While high-income Whites report slightly less illicit drug use than low-income Whites, the prevalence of lifetime illicit drug use is three times higher among Hispanics in the highest income stratum relative to those in the lowest. The drastic increase in illicit drug use for Hispanics indicates that increased income may be associated with potential risk factors for illicit drug use. However, studies suggest that foreign-born Hispanics are at significantly lower risk for illicit drug use than USborn Whites $(25,26)$, which is also consistent with our findings showing that nativity may be a protective factor for Hispanics. Hispanic and other ethnic identification has been associated with decreased illicit drug use (26). Other research has shown that close social networks and family ties are also a protective factor against illicit drug use among Hispanics (27). These studies may suggest that the lower illicit drug use among low-income Hispanics may be due to stronger social support among low-income, foreignborn Hispanics relative to their higher-income, US-born counterparts. This conclusion is supported by our multivariate results,

\section{References}

1. US Department of Health and Human Services. Mental Health: A Report of the Surgeon General. Rockville, MD: US Department of Health and Human Services, Substance Abuse and Mental Health Services Administration, Center for Mental Health Services, National Institutes of Health, National Institute of Mental Health (1999). Available from: http://www.surgeongeneral.gov/library/ mentalhealth/home.html which indicate that mental health disparities between Whites and Hispanics are largely explained after adjustment for income and nativity.

This study has several limitations. One is that we conducted secondary analyses of the AHS data, which limited our mental health outcomes and explanatory variables to those collected by AHS. Moreover, since AHS was a telephone survey, the sample may not have included those with only cell phones or those that do not have a phone. This limitation is particularly salient among lower income populations. The AHS data include sample weights that attempt to correct for the complex survey design and non-response bias, which may limit the impacts of the design on our study. A further limitation is that all measures are selfreported and thus subject to bias. The proportion of participants who self-reported as illicit drug users was small, which may have limited our statistical power to assess disparities across groups. Lastly, there were a large proportion of participants who did not provide household income information. Our analysis included only a subpopulation of those with complete information on all variables used, which may have been detrimental to our analysis. One consequence of the small prevalence of self-reported drug use was that the time frame we used in our multivariable model predicting drug use was very long (i.e., the outcome in Table 4 was lifetime illicit drug use). Lifetime drug use is a very gross variable and may not be indicative of current need for behavioral health services. Despite these limitations, the AHS is one of very few population-based studies to assess the health of the Arizona population. Little is known about health in Arizona, particularly beyond vital statistics data and data collected in large national surveys that include substantial state samples (e.g., the Behavioral Risk Factor Surveillance System). Thus, the large sample size, population-based design, inclusion of a large number of minority (i.e., Hispanic) participants, and measurement of a relative wealth of behavioral data are strengths of AHS and, in turn, this study.

In this study, we found evidence of mental health and healthcare disparities between Whites and Hispanics in Arizona. Despite similar prevalence of psychological distress, Hispanics were much less likely to have been diagnosed with a mental health condition. Furthermore, while Hispanics on average were less likely to report illicit drug use, the likelihood of illicit drug use among Hispanics greatly increased with income and among the US-born and the non-English language proficient. These disparities, combined with the rapid growth of the Hispanic population, suggest that developing culturally- and linguistically appropriate strategies to improve generally poor access and use of mental healthcare services among Hispanics is of critical public health importance. Our work should be a guide for future surveillance and intervention research on the complex relationship between race/ethnicity, socioeconomic status, mental health, and health care.

2. Kessler RC, Berglund P, Demler O, Jin R, Merikangas KR, Walters EE. Lifetime prevalence and age-of-onset distributions of DSM-IV disorders in the national comorbidity survey replication. Arch Gen Psychiatry (2005) 62:593-602. doi:10. 1001/archpsyc.62.6.617

3. Substance Abuse and Mental Health Services Administration. Results from the 2012 National Survey on Drug Use and Health: Mental Health Findings. NSDUH Series H-47, HHS Publication No. (SMA) 13-4805. Rockville, MD: Substance Abuse and Mental Health Services Administration (2013). 
4. Substance Abuse and Mental Health Services Administration. Results from the 2012 National Survey on Drug Use and Health: Mental Health Findings. Rockville, MD: Substance Abuse and Mental Health Services Administration (2013). NSDUH Series H-47, HHS Publication No. (SMA) 13-4805.

5. Alegria M, Canino G, Rios R, Vera M, Calderon J, Rusch D, et al. Inequalities in use of specialty mental health services among Latinos, African Americans, and non-Latino whites. Psychiatr Serv (2002) 53(12):1547-55. doi:10.1176/appi.ps. 53.12.1547

6. Barrio C, Palinkas LA, Yamada AM, Fuentes D, Criado V, Garcia P, et al. Unmet needs for mental health services for Latino older adults: perspectives from consumers, family members, advocates, and service providers. Community Ment Health J (2008) 44(1):57-74. doi:10.1007/s10597-007-9112-9

7. Alegria M, Chatterji P, Wells K, Cao Z, Chen CN, Takeuchi D, et al. Disparity in depression treatment among racial and ethnic minority populations in the United States. Psychiatr Serv (2008) 59(11):1264-72. doi:10.1176/appi.ps.59.11. 1264

8. Chow JCC, Jaffee K, Snowden L. Racial/ethnic disparities in the use of mental health services in poverty areas. Am J Public Health (2003) 93(5):792-7. doi:10. 2105/AJPH.93.5.792

9. Fiscella K, Franks P, Doescher MP, Saver BG. Disparities in health care by race, ethnicity, and language among the insured - findings from a national sample. Med Care (2002) 40(1):52-9. doi:10.1097/00005650-200201000-00007

10. Ojeda VD, McGuire TG. Gender and racial/ethnic differences in use of outpatient mental health and substance use services by depressed adults. Psychiatr $Q$ (2006) 77(3):211-22. doi:10.1007/s11126-006-9008-9

11. Burgess DJ, Ding YM, Hargreaves M, van Ryn M, Phelan S. The association between perceived discrimination and underutilization of needed medical and mental health care in a multi-ethnic community sample. J Health Care Poor Underserved (2008) 19(3):894-911. doi:10.1353/hpu.0.0063

12. Miranda J, Cooper LA. Disparities in care for depression among primary care patients. J Gen Intern Med (2004) 19(2):120-6. doi:10.1111/j.1525-1497.2004. 30272.x

13. Guerrero EG, Kao D, Perron BE. Travel distance to outpatient substance use disorder treatment facilities for Spanish-speaking clients. Int J Drug Policy (2013) 24(1):38-45. doi:10.1016/j.drugpo.2012.04.004

14. Sentell T, Shumway M, Snowden L. Access to mental health treatment by English language proficiency and race/ethnicity. J Gen Intern Med (2007) 22:289-93. doi:10.1007/s11606-007-0345-7

15. Kim G, Loi CXA, Chiriboga DA, Jang Y, Parmelee P, Allen RS. Limited English proficiency as a barrier to mental health service use: a study of Latino and Asian immigrants with psychiatric disorders. J Psychiatr Res (2011) 45(1):104-10. doi:10.1016/j.jpsychires.2010.04.031

16. U.S. Census Bureau. State and County QuickFacts: Arizona. Washington, DC: Government Printing Office (2014).

17. Colby SL, Ortman JM. Projections of the Size and Composition of the U.S. Population: 2014 to 2060. Current Population Reports, P25-1143. Washington, DC: U.S. Census Bureau (2014).

18. Sabo S, Shaw S, Ingram M, Teufel-Shone N, Carvajal S, de Zapien JG, et al. Everyday violence, structural racism and mistreatment at the US-Mexico border. Soc Sci Med (2014) 109:66-74. doi:10.1016/j.socscimed. 2014.02.005

19. Anderson KF, Jessie KF. Racially charged legislation and latino health disparities: the case of Arizona's SB 1070. Sociol Spectr (2014) 34(6):526-48. doi:10. 1080/02732173.2014.947452

20. Ortega AN, Rosenheck R, Alegria M, Desai RA. Acculturation and the lifetime risk of psychiatric and substance use disorders among Hispanics. J Nerv Ment Dis (2000) 188(11):728-35. doi:10.1097/00005053-200011000-00002

21. Lara M, Gamboa C, Kahramanian MI, Morales LS, Hayes Bautista DE. Acculturation and Latino health in the United States: a review of the literature and its sociopolitical context. Annu Rev Public Health (2005) 26:367-97. doi:10.1146/ annurev.publhealth.26.021304.144615
22. Burnam MA, Hough RL, Karno M, Escobar JI, Telles CA. Acculturation and lifetime prevalence of psychiatric disorders among Mexican Americans in Los Angeles. J Health Soc Behav (1987) 98:89-102. doi:10.2307/2137143

23. Cherpitel CJ, Borges G. Substance use among emergency room patients: an exploratory analysis by ethnicity and acculturation 1. Am J Drug Alcohol Abuse (2002) 28(2):287-305. doi:10.1081/ADA-120002975

24. Gfroerer JC, Tan LL. Substance use among foreign-born youths in the United States: does the length of residence matter? Am J Public Health (2003) 93(11):1892-5. doi:10.2105/AJPH.93.11.1892

25. Grant BF, Stinson FS, Hasin DS, Dawson DA, Chou SP, Anderson K. Immigration and lifetime prevalence of DSM-IV psychiatricdisorders among mexican americans and non-Hispanic whites in the United States: results from the national epidemiologic survey on alcohol and relatedconditions. Arch Gen Psychiatry (2004) 61(12):1226-33. doi:10.1001/archpsyc.61.12.1226

26. Herman-Stahl MA, Krebs CP, Kroutil LA, Heller DC. Risk and protective factors for methamphetamine use and nonmedical use of prescription stimulants among young adults aged 18 to 25. Addict Behav (2007) 32(5):1003-15. doi:10.1016/j.addbeh.2006.07.010

27. Coatsworth JD, Pantin H, Szapocznik J. Familias Unidas: a family-centered ecodevelopmental intervention to reduce risk for problem behavior among Hispanic adolescents. Clin Child Fam Psychol Rev (2002) 5(2):113-32. doi:10. 1023/A:1015420503275

28. Perna LW. The benefits of higher education: sex, racial/ethnic, and socioeconomic group differences. Rev High Educ (2005) 29(1):23-52. doi:10.1353/rhe. 2005.0073

29. Brand JE, Xie Y. Who benefits most from college? Evidence for negative selection in heterogeneous economic returns to higher education. Am Sociol $\operatorname{Rev}(2010)$ 75(2):273-302. doi:10.1177/0003122410363567

30. Arizona Health Survey. Design and Methodology of the Arizona Health Survey. Phoenix, AZ: St. Luke's Health Initiatives (2010).

31. Andrews G, Slade T. Interpreting scores of the Kessler psychological distress scale (K10). Aust N Z J Public Health (2001) 25(6):494-7. doi:10.1111/j. 1467-842X.2001.tb00310.x

32. Kessler RC, Barker PR, Colpe LJ, Epstein JF, Gfroerer JC, Hiripi E. Screening for serious mental illness in the general population. Arch Gen Psychiatry (2003) 60(2):184-9. doi:10.1001/archpsyc.60.2.184

33. US Poverty Guidelines. Federal Register. Washington, DC: US Department of Health and Human Services under the authority of 42 U.S.C. 9902(2) (2015).

34. StataCorp. Stata Statistical Software: Release 13. College Station, TX: StataCorp LP (2013).

35. Amaro H, Cortés DE. National Strategic Plan Non Hispanic Drug Abuse Research: From the Molecule to the Community. Boston, MA: Northeastern University (2003).

36. Substance Abuse and Mental Health Services Administration. Results from the 2013 National Survey on Drug Use and Health: Summary of National Findings. NSDUH Series H-48, HHS Publication No. (SMA) 14-4863. Rockville, MD: Substance Abuse and Mental Health Services Administration (2014).

37. Lillie-Blanton M, Parsons PE, Gayle H, Dievler A. Racial differences in health: not just black and white, but shades of gray. Annu Rev Public Health (1996) 17(1):411-48. doi:10.1146/annurev.pu.17.050196.002211

Conflict of Interest Statement: The authors declare that the research was conducted in the absence of any commercial or financial relationships that could be construed as a potential conflict of interest.

Copyright (c) 2015 Valdez and Langellier. This is an open-access article distributed under the terms of the Creative Commons Attribution License (CC BY). The use, distribution or reproduction in other forums is permitted, provided the original author(s) or licensor are credited and that the original publication in this journal is cited, in accordance with accepted academic practice. No use, distribution or reproduction is permitted which does not comply with these terms. 